\title{
Retromaxillary recess of the sphenoid sinus: an overlooked recess
}

\author{
Mohammad Waheed El-Anwar ${ }^{* *} \mathbb{C}$, Rania Mostafa Almolla², Diaa Bakry Eldeeb ${ }^{3} \mathbb{B}$, Tamer Abdelkader Oraby ${ }^{1}$, \\ Ahmed Abdelatty Ibrahim ${ }^{4}$ and Ahmed Abdel Fattah Nofal ${ }^{1}$
}

\begin{abstract}
Background: Retro-maxillary recess of the sphenoid sinus is an area that is yet to have appropriate description in the literature and usually overlooked. The objective of the current study was to determine the incidence and detailed description of the retromaxillary recess of the sphenoid sinus by multi-slices computed tomography (MSCT) in adults. Paranasal MSCT scan of asymptomatic adults was done for all our subjects to obtain delicate anatomical details of the recess using coronal, axial, and sagittal reformatted capability. Each sphenoid sinus in the CT was revised to find and describe the retro-maxillary recess of the sphenoid sinus regarding its extensions and dimensions.

Results: This study included 100 adult subjects (200 sphenoid sinuses); retro-maxillary recess was detected in 16.5\% (33 sides) of them using MSCT. They were distributed in 20 subjects (20\% of all examined sphenoid sinuses). Sixty-five percent of reported recesses were bilateral. Range of antero-posterior diameter (depth) of the recess was 3.9 to 14 $\mathrm{mm}$ while its width range was 1.1 to $9 \mathrm{~mm}$. The thickness of the bony septum between the recess and the maxillary sinus ranged from 0.2 to $3.2 \mathrm{~mm}$.
\end{abstract}

Conclusion: Current work described in details the retromaxillary recess in CT and its nearby surrounding important structures in all directions. From our results, it is recommended to add the retromaxillary recess of the sphenoid sinus to the preoperative $\mathrm{CT}$ checklist particularly in revision cases.

Keywords: Retromaxillary recess, Endoscopic sinus surgery, Sinus surgery, CT, FESS, Sphenoid sinus, Maxillary sinus

\section{Background}

Proper radiological study of the paranasal sinus (PNS) anatomy and their variations is critical for preoperative planning and intraoperative orientation and represent the key for safe and complete surgical procedures particularly endoscopic sinus surgery (ESS) $[1,2]$. Therefore, literature are rich with endoscopic, radiologic, and anatomic studies that provide surgeons with better orientation during ESS [1-4].

Despite these anatomic descriptions, residual disease after ESS continues to occur and is not uncommon [5-7].

\footnotetext{
*Correspondence: mwenteg1973@gmail.com

1 Otorhinolaryngology-Head and Neck Surgery Department, Faculty

of Medicine, Zagazig University, Zagazig, Egypt

Full list of author information is available at the end of the article
}

The retro-maxillary recess of sphenoid sinus was sparsely referred to in literature without detailed data on it. Thus, retromaxillary pneumatization of sphenoid sinus (SS) is yet an endoscopically important area that seems to be poorly recognized and so frequently missed during ESS, particularly for residents and surgeons with less experience. The lack of studies describing this anatomic location easily explains the paucity of knowledge to appropriately describe this region. Therefore, we have conducted this work to describe this retromaxillary recess of the sphenoid sinus to provide detailed knowledge and increase surgeon and radiologist orientation of this less overlooked area to investigate its importance. 

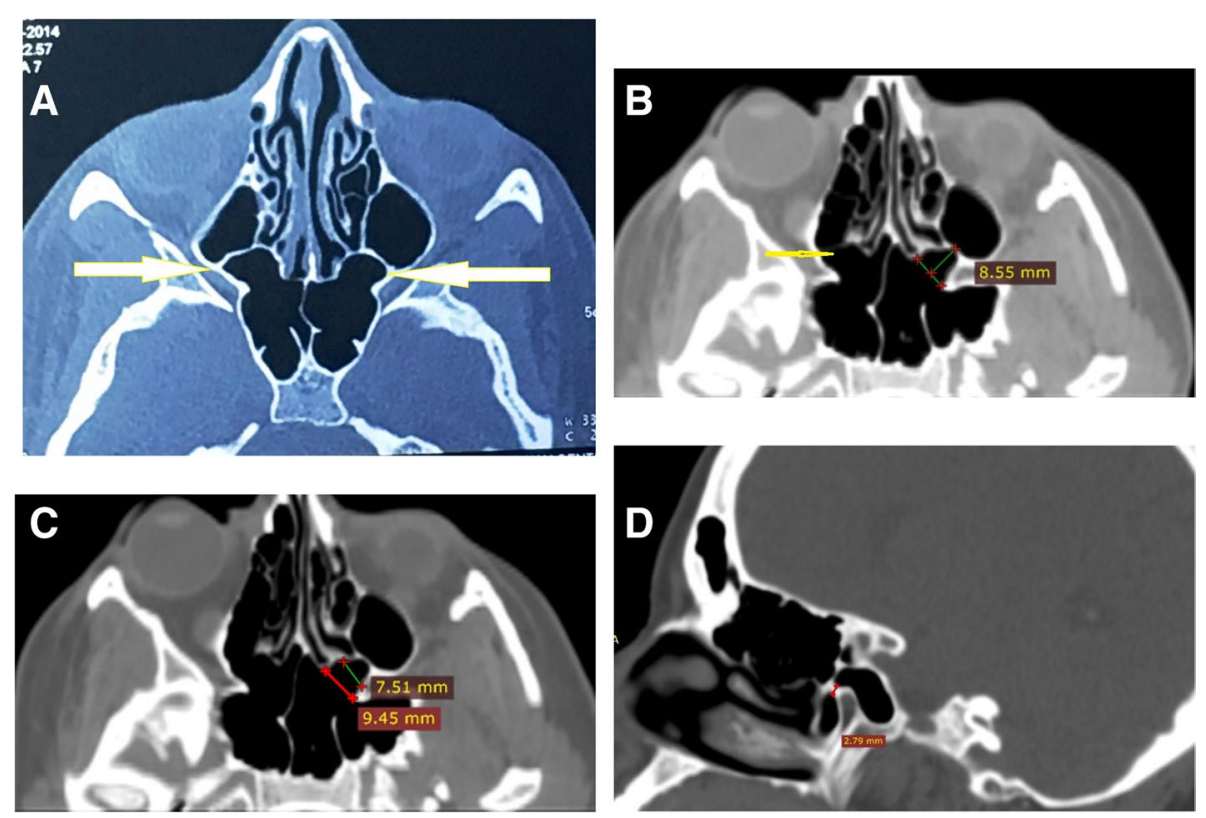

Fig. 1 A Axial MSCT showing bilateral retro-maxillary sphenoid recesses directed anteriorly and laterally (arrows) with a bony septum between it and maxillary sinus. B Showing LT sided retro-maxillary sphenoid recess and its antero-posterior dimension, note that right air filled recess (arrow) related to ethmoid not maxillary sinus and considered as lateral pneumotization of sphenoid sinus. C Showing left retro-maxillary sphenoid recess; recess width and its neck width. D Sagittal reformatted MSCT image (bone window) showing retro-maxillary sphenoid recess directed downward with a bony septum separating recess from maxillary sinus

\section{Methods}

We conducted a retrospective analysis of PNS multislice computed tomography (MSCT) scans that were obtained for adult patients as a part of evaluation of their sinonasal or anatomically related disorders.

This study was conducted in otorhinolaryngology and radiodiagnosis departments, in a tertiary teaching hospital, between January 2018 and January 2020.

The institutional review board approved the research methodology. The study was conducted according to the Declaration of Helsinki on Biomedical Research Involving Human Subjects. Detailed consents were gained before inclusion in the study.

Subjects younger than 20 years, patients who underwent previous sinonasal surgery, patients with sinonasal neoplasm or trauma, invasive fungal rhinosinusitis, or craniofacial anomalies were excluded from the study.

All MSCT examinations were performed with a 64-slice CT scan (Light speed volume VCT, GE medical system, Milwaukee, WI, USA). The protocol of 64-slice MDCT was performed with a detector width of 0.625 $\mathrm{mm}$, a section width of $1.5 \mathrm{~mm}$ and an interval reconstruction of $0.5 \mathrm{~mm}$.

Axial images were performed while the subject was in supine position and the beam was parallel to the hard palate. The cuts began from the hard palate to the top of frontal sinus (glabella), using $130 \mathrm{KV}$ and $150 \mathrm{~mA} / \mathrm{s}$ with scan time $1.5 \mathrm{~s}$. Wide window (Window widths about 1300 to 2000 and window levels about 80 to 300). High resolution algorithm was used for enhancement of the fine bony details.

Multi-planar reconstructions with delicate detail in sagittal and coronal plane were obtained for all subjects at a dedicated post-processing workstation (Advantage Windows Volume share 4.5, GE Medical System, Milwaukee, WI, USA). Films were inspected in routine standardized fashion to insure that fine details are not missed. All sphenoid sinuses in the CT were reviewed in the axial cuts searching for the retromaxillary recess of the sphenoid sinus and then coronal and sagittal reformatted cuts were done in positive cases for analysis and proper description of the recess. The recess has a direct relation to the upper aspect of the posterior wall of the maxillary sinus separated from it by a bony septum of variable thickness. This direct relationship with the maxillary sinus differentiated the recess from the usual sphenoid sinus pneumatization. Many cases have similar recess but related to the posterior air cell of the ethmoid sinus known as the lateral sphenoid recess.

The retromaxillary recess of sphenoid sinus was defined as expanded air filled recess from the lateral part of the anterior wall of the sphenoid sinus. It is directed anteriorly, laterally, and inferiorly (Fig. 1A) toward the ipsilateral maxillary sinus (upper aspect of the posterior 
wall of the maxillary sinus) from which it is separated by only a bony septum with no ethmoidal air cells or part of ptergopalatine fossa in-between.

In the axial cuts, we measured the anteroposterior diameter (depth) (Fig. 1B) of the recess, maximum width of the recess, and width of the recess neck (opening) (Fig. 1C). In sagittal reformatted image, thickness of the septum separating the recess from the maxillary sinus was measured (Fig. 1D).

Statistical analysis with the SPSS statistical software package (version 18.0; SPSS, Inc., Chicago, IL, USA) was done. $P<0.05$ was reported to be significant.

\section{Results}

One hundred adult subjects with 200 sphenoid sinuses (50\% females and 50\% male), were included in this current study. Twenty subjects $(20 \%)$ with thirty-three retromaxillary recesses $(16.5 \%$ of the investigated sphenoid sinuses) were detected. Seventeen recesses on the right side and 16 on left side. Age of those subjects ranged between 20 and 46 years (mean $27 \pm 12$ years). They were 12 females (60\%) and 8 males (40\%). Recess was unilateral in 7 (35\%) subjects (4 right and 3 left) and bilateral in 13 subjects (65\%) (Table 1). Thickness of the bony septum between the recess and the maxillary sinus ranged from 0.2 to $3.2 \mathrm{~mm}$.

Anteroposterior diameter (depth) of the recess ranged between 3.9 and $14 \mathrm{~mm}$ with a mean of $7 \pm 0.6 \mathrm{~mm}$ at the right side and $8.3 \pm 0.8 \mathrm{~mm}$ at the left side.

Width of the recess ranged between 1.1 and $9 \mathrm{~mm}$ with a mean of $6.1 \pm 0.6 \mathrm{~mm}$ at the right side and $6.4 \pm 0.7$ $\mathrm{mm}$ at the left side. In six cases (18\%), recess width was $<5 \mathrm{~mm}$ while in 27 cases (82\%) it was $\geq 5 \mathrm{~mm}$. The neck width (opening) of the reported recesses was $<5 \mathrm{~mm}$ in 9 (27\%) and $\geq 5 \mathrm{~mm}$ in 24 (73\%). Opening (entry) width ranged from 2.8 to $8.7 \mathrm{~mm}$ with a mean of $6.1 \pm 0.5 \mathrm{~mm}$ at right sides and $6.2 \pm 0.4 \mathrm{~mm}$ at left sides. Depth of the recess was significantly deeper in the left side than right side $(p<0.0001)$ while no significant differences were detected between right and left sides in other measured dimensions (Table 2).

\section{Discussion}

CT details of the maxillary and sphenoid sinuses should be well understood by the radiologists and the surgeons as a pre request in the way to perform safe and effective surgery.

The retromaxilary recess of the sphenoid sinus is related anteriorly directly to posterior maxillary wall without intervening ethmoidal air cells or pterygopalatine fossa and related medially to the nasal cavity (superior turbinate). Posteriorly, it is an air-filled recess protruded from the sphenoid sinus. Its origin from the sphenoid sinus sharply differentiates it from Haller cells and its direct relation to maxillary sinus (bony septum only between them without relation to carotid artery) differentiates it from the pterygoid pnuematization and lateral recess of the sphenoid sinus. The retromaxilary recess of the sphenoid sinus should also be differentiated from the lateral sphenoid recess, which is rather a pneumatization in the pterygoid base behind the upper part of the pterygopalatine fossa. Moreover, it is different from the previously described anterior recess of the sphenoid sinus when its anterior wall extends anteriorly beyond the plane of the sphenoidal crest [8] that may and may not have direct relation to maxillary sinus.

Table 1 Retromaxillary recessed detected in 100 studied subjects (200 sphenoid sinuses)

\begin{tabular}{ll}
\hline Retromaxillary recesses & 33 (16.5\% of studied sphenoid sinuses) \\
Subjects & 20 (20\% of studied subjects) \\
Sides & 17 on right side \\
Bilateralism & 7 Unilateral \\
Age & 18 to 46 years \\
Sex & 8 females (40\%)
\end{tabular}

Table 2 Mean dimensions of retromaxillary recess of the sphenoid sinus on both sides

\begin{tabular}{|c|c|c|c|c|}
\hline \multirow[t]{2}{*}{ Retromaxillary recess of the sphenoid sinus } & \multicolumn{2}{|c|}{ Mean \pm SD in $\mathrm{mm}$} & \multirow[t]{2}{*}{$T$ test } & \multirow[t]{2}{*}{$P$ value } \\
\hline & Right side & Left side & & \\
\hline Anteroposterior diameter (depth) & $7 \pm 0.6$ & $8.3 \pm 0.8$ & $t=5.3022$ & $<0.0001 \mathrm{~S}$ \\
\hline Width of the recess & $6.1 \pm 0.6$ & $6.4 \pm 0.7$ & $t=1.3244$ & $0.195 \mathrm{NS}$ \\
\hline Opening of the recess & $6.1 \pm 0.5$ & $6.2 \pm 0.4$ & $t=0.6319$ & $0.5321 \mathrm{NS}$ \\
\hline
\end{tabular}

SD standard deviation, $S$ significant, NS non-significant 
Retromaxilary recess of the sphenoid sinus is rarely and poorly described in the literatures to the extent that it was described at 2009 as a case report by Ciobanu et al. [9]. This recess was not mentioned in most studies that focus on the sphenoid sinus $[8,10,11]$ even in the literature review on the anatomical variations of the sphenoid sinus [12].

Because this retromaxilary recess of the sphenoid sinus has received poor attention and limited undetailed citations $[3,4,13,14]$ in the rhinologic literature as compared with other anatomic variations, in current work, we focused on CT description of such overlooked area. Therefore, we believe the current description of the retro-maxillary recess of the sphenoid sinus significantly clarifies the variations in this region and highlights the importance of this recess.

Since the maxillary sinus reaches its mature size when the permanent teeth fully develop at the age of 20 years [15], we studied CT of subjects aged $\geq 20$ years.

It is clear from the results of the current study that retromaxillary recess is not uncommon as it was found in $20 \%$ of studied subjects with nearly the same probability in the right or the left side, while $65 \%$ of reported recesses were encountered bilaterally. Similar incidence was detected by Craiu et al. [16].

In the current study, the depth of the recess (range, 3.9-14 $\mathrm{mm}$ ) was found to be longer than its width (range, 1.1-9 mm). In most recesses (82\%), the recess width was $\geq 5 \mathrm{~mm}$ and also the neck width (entry orifice) was $\geq 5 \mathrm{~mm}$ in most of the reported recesses (73\%). Thus, this area is a relatively a wide area that needs to be well visualized for any residual pathology during endoscopic sphenoid surgery reflecting the importance of utilizing angled endoscopy $\left(30^{\circ}, 45^{\circ}\right.$, or even $70^{\circ}$ ) to completely visualize and clear this hidden area.

Thickness of the bony septum (sphenomaxillary plate) between the recess and the maxillary sinus ranged from 0.2 to $3.2 \mathrm{~mm}$. Thus, undiagnosed retromaxillary recess of the sphenoid sinus could lead to open it accidentally into the middle meatus. In addition, newer approaches to this recess through the maxillary sinus (trans antral approach) could be reliable and need to be studied.

We recommend adding the retromaxillary recess of the sphenoid sinus to the preoperative CT checklist and considering it as a hidden area to avoid residual pathology taking into consideration that axial $\mathrm{CT}$ is mandatory to visualize this recess.

It is important to differentiate retromaxillary recess of the sphenoid sinus from the more common retromaxillary recess of the posterior ethmoid sinus, since sphenoid retro-maxillary extension can be spared in cases of posterior ethmoid disease.
It is expected that this study will open the door for modification of some endoscopic approaches and further work investigating the importance of this recess in ESS is required.

In addition, this recess requires attention during ESS because residual undissected retromaxillary cell could be a cause of residual in revision ESS and can contribute to inadequate disease clearance. Thus, further study of residual disease within this recess in revision cases is still needed.

The possible existence of a maxillary recess of the sphenoid sinus must be held in mind prior to interventions at the level of the lateral nasal wall and sphenoid sinus, an axial and not only coronal. CT-evaluation helps to differentiate between a Haller cell and a retromaxillary of the ethmoid sinus.

\section{Conclusion}

The retromaxillary recess of the sphenoid sinus was described in details to increase orientation to such recess and its nearby surrounding important structures in all directions. From our results, it is recommended to add the retromaxillary recess of the sphenoid sinus to the preoperative $\mathrm{CT}$ checklist particularly in revision cases.

\section{Abbreviations \\ HRCT: High-resolution computed tomography; MPR: Multiplanar reconstruc- tion; MSCT: Multislice computed tomography; SD: Standard deviation; PNS: Paranasal sinus; ESS: Endoscopic sinus surgery.}

\section{Acknowledgements}

Not applicable.

\section{Authors' contributions}

MWE: Suggest and develop research idea, review literature, tabulate and interpret data, statistical analysis, write and revise manuscript. RMA and DBE: Perform CT, collect data, review literature, write methodology, revise manuscript, prepare figures. TAO, AAl, and AAN: Review literature, assist in data interpretation, write and revise manuscript. All authors have read and approved the final manuscript.

Funding

None.

Availability of data and materials

The datasets used and/or analyzed during the current study are available from the corresponding author on reasonable request.

\section{Declarations}

Ethics approval and consent to participate

The Zagazig University institutional review board approved the research methodology. The study was conducted according to the Declaration of Helsinki on Biomedical Research Involving Human Subjects. Detailed consents were gained before inclusion in the study.

Consent for publication

Not applicable.

Competing interests

The authors declare that they have no competing interests. 


\section{Author details}

${ }^{1}$ Otorhinolaryngology-Head and Neck Surgery Department, Faculty of Medicine, Zagazig University, Zagazig, Egypt. ${ }^{2}$ Radiodiagnosis Department, Faculty of Medicine, Zagazig University, Zagazig, Egypt. ${ }^{3}$ Radiodiagnosis Department, Faculty of Medicine, Benha University, Benha, Egypt. ${ }^{4}$ Otorhinolaryngology-Head and Neck Surgery Department, Faculty of Medicine, Benha University, Benha, Egypt.

Received: 7 October 2021 Accepted: 22 October 2021

Published online: 16 November 2021

\section{References}

1. El-Anwar MW, Khazbak AO, Eldib DB, Algazzar HY (2018) Lamina papyracea position in patients with nasal polypi: a computed tomography analysis. Auris Nasus Larynx 45(3):487-491

2. El-Anwar MW, Raafat A, Almolla RM, Alsowey AM, Elzayat S (2018) Maxillary sinus ostium assessment: a CT study. Egypt J Radiol Nucl Med 49(4):1009-1013

3. Nouraei SA, Elisay AR, Dimarco A, Abdi R, Majidi H, Madani SA, Andrews PJ (2009) Variations in paranasal sinus anatomy: implications for the pathophysiology of chronic rhinosinusitis and safety of endoscopic sinus surgery. J Otolaryngol Head Neck Surg. 38:32-37

4. Kantarci M, Karasen RM, Alper F, Onbas O, Okur A, Karaman A (2004) Remarkable anatomic variations in paranasal sinus region and their clinical importance. Eur J Radiol. 50:296-302

5. Gore MR, Ebert CS Jr, Zanation AM, Senior BA (2013) Beyond the "central sinus": radiographic findings in patients undergoing revision functional endoscopic sinus surgery. Int Forum Allergy Rhinol. 3:139-146

6. Khalil HS, Eweiss AZ, Clifton N (2011) Radiological findings in patients undergoing revision endoscopic sinus surgery: a retrospective case series study. BMC Ear Nose Throat Disord 7(11):4

7. Musy PY, Kountakis SE (2004) Anatomic findings in patients undergoing revision endoscopic sinus surgery. Am J Otolaryngol. 25:418-422
8. Hiremath SB, Gautam AA, Sheeja K, Benjamin G (2018) Assessment of variations in sphenoid sinus pneumatization in Indian population: a multidetector computed tomography study. Indian J Radiol Imaging 28:273-279

9. Ciobanu IC, Motoc A, Jianu AM, Cergan R, Banu MA, Rusu MC (2009) The maxillary recess of the sphenoid sinus. Rom J Morphol Embryol 50(3):487-489

10. Anusha B, Baharudin A, Philip R, Harvinder S, Shaffie BM, Ramiza RR (2015) Anatomical variants of surgically important landmarks in the sphenoid sinus: a radiologic study in Southeast Asian patients. Surg Radiol Anat. 37(10):1183-1190

11. Dal Secchi MM, Dolci RLL, Teixeira R, Lazarini PR (2018) An analysis of anatomic variations of the sphenoid sinus and its relationship to the internal carotid artery. Int Arch Otorhinolaryngol. 22(2):161-166

12. Anusha B, Baharudin A, Philip R, Harvinder S, Shaffie BM (2014) Anatomical variations of the sphenoid sinus and its adjacent structures: a review of existing literature. Surg Radiol Anat. 36(5):419-427

13. Meloni F, Mini R, Rovasio S, Stomeo F, Teatini GP (1992) Anatomic variations of surgical importance in ethmoid labyrinth and sphenoid sinus: a study of radiological anatomy. Surg Radiol Anat. 14:65-70

14. Selcuk A, Ozcan KM, Akdogan O, Bilal N, Dere H (2008) Variations of maxillary sinus and accompanying anatomical and pathological structures. Craniofac Surg. 19:159-164

15. Jovanic S, Jelicic N, Kargovska-Klısarova A (1984) Postnatal development and reports of the maxillary sinus. Acta Anat 118:122-128

16. Craiu C, Rusu MC, Hostiuc S, Săndulescu M, Derjac-Aramă A (2017) Anatomic variation in the pterygopalatine angle of the maxillary sinus and the maxillary bulla. Anat Sci Int. 92(1):98-106

\section{Publisher's Note}

Springer Nature remains neutral with regard to jurisdictional claims in published maps and institutional affiliations.

\section{Submit your manuscript to a SpringerOpen ${ }^{\circ}$ journal and benefit from:}

- Convenient online submission

- Rigorous peer review

- Open access: articles freely available online

- High visibility within the field

- Retaining the copyright to your article

Submit your next manuscript at $\boldsymbol{\nabla}$ springeropen.com 